\title{
Effect of irradiance on growth, photosynthesis, pigment content and nutrient consumption in dense cultures of Rhodomonas salina (Wislouch) (Cryptophyceae)
}

\section{Efecto de la irradiancia en el crecimiento, fotosíntesis, contenido pigmentario y consumo de nutrientes en cultivos densos de Rhodomonas salina (Wislouch) (Cryptophyceae)}

\author{
A. Bartual ${ }^{1 *}$ \\ L. M. Lubián ${ }^{2}$ \\ J.A. Gálvez ${ }^{1}$ \\ F. X. Niell ${ }^{3}$ \\ ${ }^{1}$ Departamento de Biología, Facultad de Ciencias del Mar y Ambientales \\ Universidad de Cádiz \\ 11510-Puerto Real, Cádiz, Spain \\ *E-mail: ana.bartual@uca.es \\ ${ }^{2}$ Instituto de Ciencias Marinas de Andalucía, ICMAN \\ Consejo Superior de Investigaciones Científicas (C.S.I.C.) \\ 11510-Puerto Real, Cádiz, Spain \\ ${ }^{3}$ Departamento de Ecología, Facultad de Ciencias \\ Universidad de Málaga \\ 29071-Málaga, Spain
}

Recibido en junio de 2002; aceptado en septiembre de 2002

\begin{abstract}
The effects of different incident irradiances on growth, photosynthesis, pigment content and nutrient uptake were studied in dense cultures of the cryptophyte Rhodomonas salina (Wislouch) Hill y Wetherbee. Cells were grown for ten days at different incident irradiances: 11, 33, 75, 260 and $320 \mu \mathrm{mol}$ photon $\mathrm{m}^{-2} \mathrm{~s}^{-1}$. The average pigment content (phycoerythrin and chlorophyll $a$ ) was lower when cells were grown at high irradiances ( 260 and $320 \mu \mathrm{mol}$ photon $\left.\mathrm{m}^{-2} \mathrm{~s}^{-1}\right)$ compared with cells grown under low irradiances $\left(11,33\right.$ and $75 \mu \mathrm{mol}$ photon $\left.\mathrm{m}^{-2} \mathrm{~s}^{-1}\right)$.The maximum photosynthetic rate $\left(P_{\max }\right)$ was maximal at $75 \mu$ mol photon $\mathrm{m}^{-2} \mathrm{~s}^{-1}$ , decreasing considerably at the highest irradiance in which apparent photosynthetic efficiency per cell and per chlorophyll $a$ unit $\left(\alpha_{c e l l}\right.$ and $\left.\alpha_{\text {chla }}\right)$ also decreased. Results showed that dense cultures of $R$. salina grew optimally in a range between 75 and 260 $\mu \mathrm{mol}$ photon $\mathrm{m}^{-2} \mathrm{~s}^{-1}$ with optimal photosynthetic performance at $75 \mu \mathrm{mol}$ photon $\mathrm{m}^{-2} \mathrm{~s}^{-1}$. Nitrogen and phosphorus depletion occurred as a consequence of the exponential growth, except under the lowest and the highest irradiances (11 and $320 \mu \mathrm{mol}$ photon $\mathrm{m}^{-2} \mathrm{~s}^{-1}$, respectively). Associated to N-limitation, phycoerythrin (PE) and chlorophyll $a$ decreased considerably. It is suggested that R.salina responds to nitrogen-depleted conditions by mobilizing nitrogen from PE, this behaviour being modelled by a relationship between external nitrogen availability and PE mobilization.
\end{abstract}

Key words: Cryptophyceae, photoacclimation, phycoerythrin, P-I curves, Rhodomonas salina.

\section{Resumen}

En este trabajo se analizan los efectos que diferentes irradiancias incidentes tienen en el crecimiento, características fotosintéticas, contenido pigmentario e incorporación de nutrientes en cultivos densos de la criptofita Rhodomonas salina (Wislouch) Hill y Wetherbee. Con tal fin, se mantuvieron cultivos durante diez días bajo distintas condiciones de luz incidente: $11,33,75,260$ y $320 \mu \mathrm{mol}$ fotón $\mathrm{m}^{-2} \mathrm{~s}^{-1}$. El contenido pigmentario promedio (ficoeritrina y clorofila $a$ ) fue menor en células adaptadas a las mayores irradiancias $\left(260\right.$ y $320 \mu \mathrm{mol}$ fotón $\left.\mathrm{m}^{-2} \mathrm{~s}^{-1}\right)$ en comparación con las adaptadas a las irradiancias menores $\left(11,33\right.$ y $75 \mu \mathrm{mol}$ fotón $\left.\mathrm{m}^{-2} \mathrm{~s}^{-1}\right)$. El valor máximo de fotosíntesis $\left(P_{\max }\right)$ se obtuvo para las células adaptadas a $75 \mu$ mol fotón $\mathrm{m}^{-2} \mathrm{~s}^{-1}$, decreciendo considerablemente para la irradiancia máxima ensayada en la que también la eficiencia fotosintética $\left(\alpha_{c e l .}\right.$ and $\left.\alpha_{c l a}\right)$ fue menor. Los resultados muestran que esta criptofita crece óptimamente en cultivos densos en un rango de irradiancias incidentes entre 75 y $260 \mu \mathrm{mol}$ fotón $\mathrm{m}^{-2} \mathrm{~s}^{-1}$, con una actividad fotosintética óptima a $75 \mu \mathrm{mol}$ fotón $\mathrm{m}^{-2} \mathrm{~s}^{-1}$. Como consecuencia del crecimiento exponencial de los cultivos, se produjo una desaparición paulatina y prácticamente total del nitrógeno y el fósforo del medio, excepto en los cultivos adaptados a las irradiancias máxima $\left(320 \mu \mathrm{mol}\right.$ fotón $\left.\mathrm{m}^{-2} \mathrm{~s}^{-1}\right)$ y mínima 
(11 $\mu \mathrm{mol}$ fotón $\mathrm{m}^{-2} \mathrm{~s}^{-1}$ ) empleadas. Asociada a tales condiciones de limitación de nitrógeno se observó una disminución del contenido celular de ficoeritrina y clorofila $a$, definiéndose una clara relación entre la disponibilidad de nitrógeno externo y la tasa de desaparición de ficoeritrina. Estos resultados sugieren que Rhodomonas salina es capaz de movilizar el nitrógeno asociado a la ficoeritrina como respuesta ante condiciones de baja disponibilidad de dicho nutriente.

Palabras clave: Cryptophyceae, fotoaclimatación, ficoeritrina, curvas P-I, Rhodomonas salina.

\section{Introduction}

The influence of irradiance on the photosynthesis of autotrophic microalgae has been one of the topics most thoroughly studied. In the literature, these studies have been oriented on a physiological way or in a more applied direction. Strict physiological works have been focused in the description of strategies of photoacclimation based on the analysis of changes in the photosynthetic parameters, classically related with the alteration in the number or size of photosynthetic units (PSUs; Prézelin, 1981) and/or pigments content. In this type of studies, low cell density cultures are required to avoid changes on quality or quantity of incident light (i.e. self shading) during cell growth (see reviews by Richardson et al., 1983; Henley, 1993). On the other hand, in more applied researches massive algal cultures have been used in which reduced light penetration and increased pigmentation lead to a reduction in the efficiency of photosynthetic energy conversion (Sukenik et al., 1987), but are necessary for getting a high algal biomass since the enhancement of phytoplankton productivity has been their main objective (Grobbelaar et al., 1996; Eriksen et al., 1996).

The genus Rhodomonas can be considered as a potentially interesting microalgae for aquaculture because of its high percentange of polyunsatured fatty acids (Fernández-Reiriz et al., 1989; Zhukova and Aizdaicher, 1995). All these arguments make interesting to analize the effect of different incident irradiances on growth and photosynthesis on this cryptophyte, specially in dense cultures used for applied research. The very first studies on cryptophytes reported data of ultrastructure (Dodge, 1969) and heterotrophic nutrition (Ukeles and Rose, 1976) but more recent physiological research on this group have been oriented towards nutrient depletion and the structure of its photosynthetic apparatus (Lewitus and Caron, 1990; Eriksen and Iversen, 1995). On the other hand, the applied studies on cryptophytes have been centered on the analysis of parameters that could affect their biochemical (Fernández-Reiriz et al. 1989; Kitano et al., 1997; Renaud et al., 2002) and elemental composition (Vrede, 1998). However, only one work has been conducted to describe photosynthesis-irradiance (P-I) relationships in a marine cryptophyte, namely Cryptomonas strain Lis (Thinh, 1988).

On the basis of this bibliography, the aims of our study have been, first, to examine the effect of different incident irradiances on the photosynthetic performance of dense aerated cultures of Rhodomonas salina (Wislouch) Hill and Wetherbee (1989) (synonyms = Cryptomonas salina Wislouch = Chroomonas salina Butcher = Pyrenomonas salina Santore), commonly used for applied research in aquaculture; second, to define the optimal range of light regimes for growth and photosynthesis to enhance algal mass production; and third, to

\section{Introducción}

La influencia de la irradiancia en la fotosíntesis de microalgas autótrofas ha sido objeto de numerosos trabajos de investigación. En la bibliografía estos estudios se han orientado bien desde un punto de vista estrictamente fisiológico, o bien, desde un punto de vista más aplicado. Los trabajos fisiológicos se han centrado en la descripción de las estrategias de fotoaclimatación de las distintas especies de microalgas, a partir del análisis de los cambios en los parámetros fotosintéticos clásicamente relacionados con la alteración del número o del tamaño de las unidades fotosintéticas (PSUs; Prézelin, 1981) y/ o el contenido pigmentario. En este tipo de estudios es necesaria la utilización de cultivos de baja densidad celular que evite cambios excesivos en la calidad o cantidad de la luz incidente (ej. autosombreado) durante el crecimiento algal (ver revisiones de Richardson et al., 1983; Henley, 1993). Por otro lado, los estudios más aplicados han usado cultivos masivos de microalgas en los que la atenuación de la luz incidente y el aumento de la pigmentación reducen la eficiencia fotosintética (Sukenik et al., 1987), pero que son necesarios para la obtención de gran cantidad de biomasa algal. Estos trabajos tienen como objetivo principal optimizar la productividad fitoplanctónica (Grobbelaar et al., 1996; Eriksen et al., 1996).

El género Rhodomonas puede ser considerado como un grupo potencialmente importante para la acuicultura debido a su gran contenido en ácidos grasos poli-insaturados (Fernández-Reiriz et al., 1989; Zhukova y Aizdaicher, 1995). Todos estos argumentos nos plantearon como un objetivo interesante analizar el efecto de diferentes irradiancias incidentes en el crecimiento y fotosíntesis de esta criptofita, especialmente en cultivos densos con un fin más aplicado. Los primeros estudios sobre criptofitas recogieron fundamentalmente datos sobre la ultraestrucutra (Dodge, 1969) y nutrición heterotrófica (Ukeles y Rose, 1976). Estudios fisiológicos más recientes en este grupo algal se han orientado en el estudio del efecto de la escasez de nutrientes en la estructura del aparato fotosintético (Lewitus y Caron, 1990; Eriksen e Iversen, 1995) y por otro lado, los estudios más aplicados se han centrado en el análisis de los principales parámetros que afectan a la composición bioquímica (Fernandez-Reiriz et al. 1989; Kitano et al., 1997; Renaud et al., 2002) y elemental (Vrede, 1998) de este grupo. Sin embargo, únicamente un trabajo se ha centrado en una descripción algo más detallada de las relaciones fotosíntesis-irradiancia en una criptofita marina, Cryptomonas cepa Lis (Thinh, 1988).

En base a esta bibliografía, los objetivos de nuestro estudio han sido, en primer lugar, examinar el efecto de diferentes irradiancias incidentes en las características fotosintéticas de 
analyze changes in pigment content and the effect of nutrient depletion in batch cultures under different light conditions for understanding the major factors that control such modifications.

\section{Material and methods}

Rhodomonas salina (Wislouch) Hill and Wetherbee was obtained from the culture collection of the Instituto de Ciencias Marinas de Andalucía (C.S.I.C, Cádiz, Spain). Cultures of $R$. salina were grown in sterilized 2-L flasks containing $0.2 \mu \mathrm{m}$ of sterilized natural seawater enriched with $\mathrm{f} / 2$ medium $(1 \mathrm{~mL}$ $\mathrm{L}^{-1}$; Guillard and Ryther, 1962) and maintained at $19 \pm 1{ }^{\circ} \mathrm{C}$ with an aeration rate of $1.5 \mathrm{~L} \mathrm{~min}^{-1}$ through $0.45-\mu \mathrm{m}$ filters. After acclimation to different incident irradiances $(11,33,75$, 260 and $320 \mu \mathrm{mol}$ photon $\mathrm{m}^{-2} \mathrm{~s}^{-1}$ ) an exponential growing population of a preacclimated culture was inoculated (initial cell density of $0.15 \times 10^{6}$ cells $\mathrm{mL}^{-1}$ ) into fresh medium to start the experiment. Triplicate cultures were maintained at each incident irradiance. Continuous illumination was provided by daylight fluorescent lamps (OSRAM, L36W/10). Incident irradiance was measured with a LICOR LI-1000 radiometer equipped with a LiCor LI-193SA spherical quantum sensor. Daily, the cell number (Neubauer chamber, magnification $\times 25$ ), the pigment content and the nutrient concentration in the media were quantified. Chlorophyll $a$ (Talling and Driver, 1974), $c$ (Jeffrey and Haxo, 1968) and total carotenoids (Strickland and Parsons, 1968) were extracted in pure methanol and measured spectrophotometrically. Phycoerythrin was extracted after two cycles of freezing in $0.2 \mathrm{M}$ phosphate buffer at $\mathrm{pH} 6.8$ and determined spectrophotometrically using an absorbance coefficient of $12.6 \mathrm{~mL} \mathrm{mg}^{-1} \mathrm{~cm}^{-1}$ (MacColl et al., 1976). Inorganic nitrogen (nitrate + nitrite) and phosphate were measured using a Technicon TRAACS 800 Autoanalyzer, following the Grasshoff et al. (1983) procedures.

Growth curves were obtained from the average of triplicate cultures. Thus, specific growth rates $\left(\mathrm{d}^{-1}\right)$ were calculated from linear regression of $\operatorname{Ln}$ (cell number) $v s$ time over the first four days. The growth rate of $R$. salina cultured under another irradiance, $120 \mu \mathrm{mol}$ photon $\mathrm{m}^{-2} \mathrm{~s}^{-1}$, was also studied to provide data on the $\mu$-irradiance relationships.

Three of the five different light treatments studied were selected for comparing P-I curves: light-limited $(11 \mu \mathrm{mol}$ photon $\left.\mathrm{m}^{-2} \mathrm{~s}^{-1}\right)$, light-sub-saturated $\left(75 \mu \mathrm{mol}\right.$ photon $\left.\mathrm{m}^{-2} \mathrm{~s}^{-1}\right)$ and light-saturated $\left(320 \mu \mathrm{mol}\right.$ photon $\left.\mathrm{m}^{-2} \mathrm{~s}^{-1}\right)$ growth conditions. Triplicate P-I curves were obtained for each light condition on exponential growing cultures. This corresponded to day 6 for the light-limited growth $\left(11 \mu \mathrm{mol}\right.$ photon $\left.\mathrm{m}^{-2} \mathrm{~s}^{-1}\right)$ and day 4 for the subsaturated and saturated growth conditions (75 and $320 \mu \mathrm{mol}$ photon $\mathrm{m}^{-2} \mathrm{~s}^{-1}$, respectively). To avoid a great loss of volume in a particular culture at the end of the experimental period a mix of equal volumes from each flask was used to obtain the P-I curves. The photosynthesis was measured with a Hansatech polarographic $\mathrm{O}_{2}$ electrode (Hansatech-LD2). cultivos aireados y densos de Rhodomonas salina (Wislouch) Hill y Wetherbee (1989) (sinónimos = Cryptomonas salina Wislouch $=$ Chroomonas salina Butcher $=$ Pyrenomonas salina Santore), usada comúnmente en acuicultura; en segundo lugar, definir el rango de irradiancias para un crecimiento y actividad fotosintéticas óptimos para mejorar la producción algal y, por último, analizar los cambios pigmentarios y el efecto de la desaparición de nutrientes en cultivos cerrados bajo distintas intensidades de luz así como los principales factores que controlan dichas alteraciones.

\section{Material y métodos}

Rhodomonas salina (Wislouch) Hill y Wetherbee se obtuvo de la colección de cultivos de microalgas marinas del Instituto de Ciencias Marinas de Andalucía (C.S.I.C., Cádiz, España).

Se trabajó con cultivos cerrados de $R$. salina preparados en matraces de $2 \mathrm{~L}$ con agua de mar natural filtrada por $0.2 \mu \mathrm{m}$, esterilizada en autoclave y enriquecida con medio $\mathrm{f} / 2$ (1 $\mathrm{mL} \mathrm{L}^{-1}$; Guillard y Ryther, 1962). Dichos cultivos se mantuvieron a una temperatura de $19 \pm 1{ }^{\circ} \mathrm{C}$ y fueron aireados a una tasa de $1.5 \mathrm{~L} \mathrm{~min}^{-1}$ con aire filtrado por $0.45 \mu \mathrm{m}$. Tras la preaclimatación a diferentes irradiancias incidentes $(11,33,75$, 260 and $320 \mu \mathrm{mol}$ fotón $\mathrm{m}^{-2} \mathrm{~s}^{-1}$ ) los cultivos en fase exponencial se inocularon por triplicado en medio fresco para comenzar el experimento (densidad celular inicial de $0.15 \times 10^{6}$ cel. $\mathrm{mL}^{-1}$ ). Se empleó luz continua emitida por tubos fluorescentes "daylight" (OSRAM, L36W/10). Las irradiancias incidentes se midieron con un radiómetro LICOR LI-1000 equipado con un sensor esférico LiCor LI-193SA. Diariamente se cuantificaron la densidad celular (cámara Neubauer, aumentos $\times 25$ ), el contenido pigmentario y la concentración de nutrientes en el medio. Las clorofilas $a$ (Talling y Driver, 1974), $c$ (Jeffrey y Haxo, 1968) y los carotenoides totales (Strickland y Parsons, 1968) se extrajeron en metanol puro y se cuantificaron espectrofotométricamente. La ficoeritrina se extrajo tras dos ciclos de congelación en tampón fosfato $0.2 \mathrm{M}$ a pH 6.8 y se cuantificó espectrofotométricamente usando un coeficiente de absorbancia de $12.6 \mathrm{~mL} \mathrm{mg}^{-1} \mathrm{~cm}^{-1}$ (MacColl et al., 1976). El nitrógeno inorgánico (nitrato + nitrito) y el fosfato del medio se cuantificaron usando un autoanalizador de flujo segmentado modelo TECHNICON TRAACS 800 siguiendo los protocolos propuestos por Grasshoff et al. (1983).

Las curvas de crecimiento se obtuvieron a partir del promedio de cultivos por triplicado. Las tasas específicas de crecimiento $\left(\mathrm{d}^{-1}\right)$ se calcularon a partir de la regresión lineal de Ln (número de células) $v s$ tiempo en los primeros cuatro días de crecimiento. Para completar la curva de crecimiento vs irradiancia, se estudió también la tasa de crecimiento de cultivos adaptados a otra irradiancia incidente, $120 \mu \mathrm{mol}$ fotón $\mathrm{m}^{-2} \mathrm{~s}^{-1}$.

La fotosíntesis se estudió mediante la obtención de curvas fotosíntesis-irradiancia (curvas P-I). Para ello se seleccionaron tres de los 5 tratamientos de luz estudiados: células en condiciones limitantes para el crecimiento $\left(11 \mu \mathrm{mol}\right.$ fotón $\left.\mathrm{m}^{-2} \mathrm{~s}^{-1}\right)$, en 
Using a combination of optically neutral filters, 11 incident irradiances $(6,10,14,25,29,54,100,171,320,500$ and 1200 $\mu \mathrm{mol}$ photon $\mathrm{m}^{-2} \mathrm{~s}^{-1}$ ) were obtained. The values of initial slopes of the P-I curves $(\alpha)$ were obtained from the linear regression of light-dependent values of $\mathrm{O}_{2}$ evolution. The observed $P_{\text {max }}$ were compared.

The effect of acclimation to different incident irradiances on the variables studied were compared for the significance of the differences observed. The growth rates and the slopes of the P-I curves $(\alpha ; n=3)$ at different irradiances were compared in pairs, using a two-slope comparison test by simple linear regression (Zar, 1984). The significance levels were set at $P<0.05$.

\section{Results}

Growth

Irradiances between 75 and $320 \mu \mathrm{mol}$ photon $\mathrm{m}^{-2} \mathrm{~s}^{-1}$ had no significant differences on growth rates, with an average value of $0.74 \pm 0.05 \mathrm{~d}^{-1}$ ( $t$-test, $P<0.05$; fig. 1$)$. This range can be considered as an optimal growth intensity for $R$. salina. Limited growth occurred at $11 \mu \mathrm{mol}$ photon $\mathrm{m}^{-2} \mathrm{~s}^{-1}(0.43 \pm$ $\left.0.08 \mathrm{~d}^{-1}\right)$, the lowest irradiance applied in this study. The growth rates $v s$ irradiance $(\mu-\mathrm{I})$ curve obtained for $R$. salina is in agreement with such relationships obtained for different strains of cryptophytes by Ojala (1993).

Photosynthetic pigments

The $\mathrm{PE} / \mathrm{Chl} a$ ratio was higher at lower irradiances $(11,33$ and $75 \mu \mathrm{mol}$ photon $\mathrm{m}^{-2} \mathrm{~s}^{-1}$ ) compared with higher irradiances

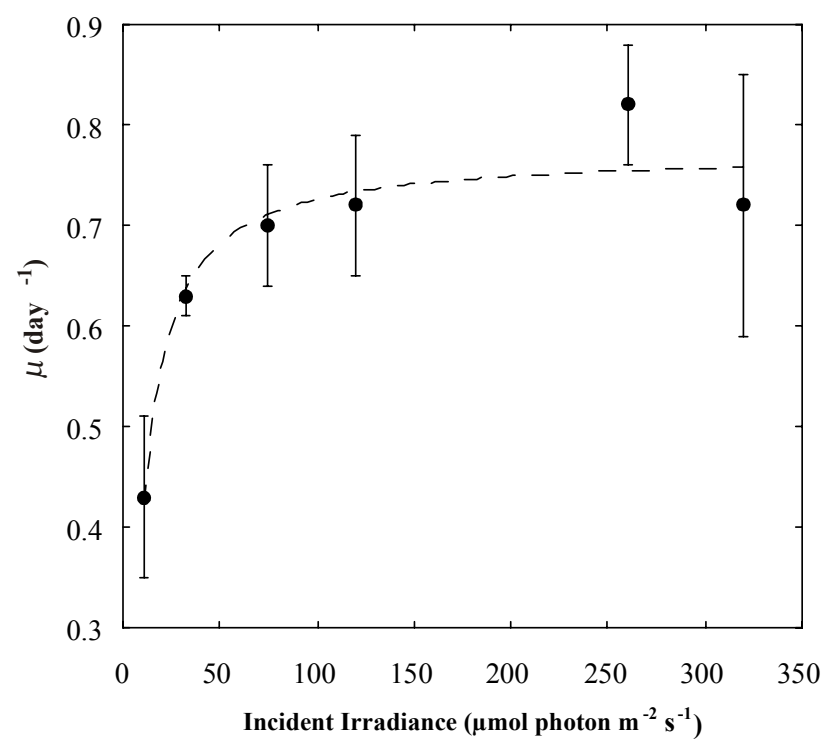

Figure 1. Growth $\left(\mu ; d^{-1}\right)$ vs incident irradiance $\left(l ; \mu\right.$ mol photon $\left.\mathrm{m}^{-2} \mathrm{~s}^{-1}\right)$ in Rhodomonas salina.

Figura 1. Crecimiento $\left(\mu ; d^{-1}\right)$ vs irradiancia incidente $\left(l ; \mu\right.$ mol fotón $\left.\mathrm{m}^{-2} \mathrm{~s}^{-1}\right)$ en Rhodomonas salina. condiciones subsaturantes $\left(75 \mu \mathrm{mol}\right.$ fotón $\left.\mathrm{m}^{-2} \mathrm{~s}^{-1}\right)$ y en condiciones saturantes $\left(320 \mu \mathrm{mol}\right.$ fotón $\left.\mathrm{m}^{-2} \mathrm{~s}^{-1}\right)$. Para cada tratamiento de luz seleccionado se obtuvieron tres curvas P-I en cultivos en fase exponencial de crecimiento. Esto coincidió con el día 6 de crecimiento en el cultivo en condición de luz limitante $\left(11 \mu \mathrm{mol}\right.$ fotón $\left.\mathrm{m}^{-2} \mathrm{~s}^{-1}\right)$ y con el día 4 para condiciones de luz subsaturante y saturante $\left(75\right.$ y $320 \mu \mathrm{mol}$ fotón $\mathrm{m}^{-2} \mathrm{~s}^{-1}$, respectivamente). Para obtener las curvas P-I se empleó una mezcla de volúmenes equivalentes de cada matraz para cada irradiancia estudiada, evitando así una pérdida excesiva de volumen en los cultivos en los dias posteriores de seguimiento hasta completar el experimento. Las tasas de fotosíntesis se midieron empleando un electrodo de oxígeno tipo Clark (Hansatech-LD2). Mediante la combinación de diferentes filtros neutros se consiguieron 11 irradiancias incidentes $(6,10$, $14,25,29,54,100,171,320,500$ y $1200 \mu$ mol fotón $\mathrm{m}^{-2} \mathrm{~s}^{-1}$ ). Los valores de la pendiente inicial de las curvas P-I $(\alpha)$ se obtuvieron mediante regresión lineal de los valores de evolución de oxígeno de la porción de la curva P-I dependiente de la luz. En cuanto a la fotosíntesis máxima $\left(P_{\max }\right)$, se compararon los valores observados.

Se estudió la significancia de las diferencias observadas en el efecto de la aclimatación a la luz de las variables estudiadas. Se compararon por pares las tasas de crecimiento y las pendientes de las curvas P-I $(\alpha)(n=3)$ a diferentes irradiancias, usando un test de comparación de pendientes por regresión lineal simple (Zar, 1984). El nivel de significancia se estableció en $P<0.05$.

\section{Resultados}

Crecimiento

No se observaron diferencias significativas en las tasas de crecimiento obtenidas en cultivos adaptados entre 75 y 320 $\mu \mathrm{mol}$ fotón $\mathrm{m}^{-2} \mathrm{~s}^{-1}$, con un valor promedio de $\mu=0.74 \pm$ $0.05 \mathrm{~d}^{-1}$ ( $t$-test, $P<0.05$; fig. 1 ). Este rango de intensidades de luz puede ser considerado como un rango óptimo para $R$. salina. El crecimiento se vió limitado a $11 \mu \mathrm{mol}$ fotón $\mathrm{m}^{-2} \mathrm{~s}^{-1}$ $\left(0.43 \pm 0.08 \mathrm{~d}^{-1}\right)$, la menor de las irradiancias ensayadas. La curva crecimiento $v s$ irradiancia $(\mu-\mathrm{I})$ obtenida para $R$. salina coincidió con el tipo de relaciones obtenidas para otras criptofitas por Ojala (1993).

Pigmentos fotosintéticos

El cociente ficoeritrina/clorofila $a(\mathrm{PE} / \mathrm{Cl} a)$ fue mayor a las menores irradiancias $\left(11,33\right.$ y $75 \mu$ mol fotón $\left.\mathrm{m}^{-2} \mathrm{~s}^{-1}\right)$ en comparación con las irradiancias mayores (fig. 2a,b). Tales diferencias fueron especialmente patentes durante los cuatro primeros días de crecimiento. La evolución temporal del contenido celular de ficoeritrina (PE; fig. 2b) coincidió con la disminución en la disponibilidad de nitrógeno inorgánico y fosfato del medio (fig. 2c, d) con la excepción de las células adaptadas 
(fig. 2a,b). Such differences were specially noticeable during the first four days of growth. The time course of phycoerythrin content (scaled by cell) (fig. 2b) was in accordance with the decrease in inorganic nitrogen and phosphate in the culture media (fig. 2c, d) with the exception of cells grown under limited $\left(11 \mu \mathrm{mol}\right.$ photon $\left.\mathrm{m}^{-2} \mathrm{~s}^{-1}\right)$ and saturated irradiances (320 $\mu$ mol photon $\mathrm{m}^{-2} \mathrm{~s}^{-1}$ ) in which neither nitrogen nor phosphate were exhausted throughout the experiment. In such treatments the nitrate concentration never decreased below 1.5 and 0.5 $\mathrm{mM}$, respectively (fig. $2 \mathrm{c}, \mathrm{d}$ ). The decrease of PE over time can be fitted to a negative exponential function:

$$
\mathrm{PE}=\mathrm{PE}_{0} \times \mathrm{e}^{-\left[K_{\mathrm{PE}}\left(t-t_{i}\right)\right]}
$$

where $\mathrm{PE}=$ phycoerythrin content $\left(\mathrm{pg}\right.$ cell $\left.^{-1}\right), \mathrm{PE}_{0}=$ theoretical $\mathrm{PE}\left(\mathrm{pg}\right.$ cell $^{-1}$ ) at time $\left(t-t_{i}\right)=0, K_{\mathrm{PE}}=$ decreasing rate of cellular $\mathrm{PE}\left(\mathrm{day}^{-1}\right), t=$ time (days) and $t_{i}=$ initial time period (days) with no exponential decrease. Except for cells acclimated to 11 $\mu \mathrm{mol}$ photon $\mathrm{m}^{-2} \mathrm{~s}^{-1}$, in which the decrease of pigments and nutrients was much lower, $r^{2}>0.95$ (table 1).

Nutrient dynamics

As it is observed on figure $2 \mathrm{c}, \mathrm{d}$, the time course of nutrient-depletion evolution showed two phases, the first phase a condiciones de luz limitante (11 $\mu$ mol fotón $\left.\mathrm{m}^{-2} \mathrm{~s}^{-1}\right) \mathrm{y}$ saturante $\left(320 \mu \mathrm{mol}\right.$ fotón $\left.\mathrm{m}^{-2} \mathrm{~s}^{-1}\right)$ en las que en ningún momento se consumió la totalidad de los nutrientes disponibles. En dichos tratamientos, la concentración de nitrógeno nunca fue inferior a 1.5 y $0.5 \mathrm{mM}$, respectivamente (fig. 2c, d). La disminución de PE a lo largo del tiempo se ajustó a una función exponencial negativa:

$$
\mathrm{PE}=\mathrm{PE}_{0} \times \mathrm{e}^{-\left[K_{\mathrm{PE}}\left(t-t_{i}\right)\right]}
$$

donde $\mathrm{PE}=$ contenido celular de ficoeritrina $\left(\mathrm{pg} \mathrm{cel}{ }^{-1}\right)$, $\mathrm{PE}_{0}=$ contenido celular teórico de ficoeritrina $\left(\mathrm{pg} \mathrm{cel}^{-1}\right)$ al tiempo $\left(t-t_{i}\right)=0, K_{\mathrm{PE}}=$ tasa de desaparición de $\mathrm{PE}\left(\mathrm{d}^{-1}\right)$, $t=$ tiempo (días) y $t_{i}=$ periodo de tiempo inicial (días) $\sin$ decrecimiento exponencial. Con excepción de las células cultivadas a $11 \mu \mathrm{mol}$ fotón $\mathrm{m}^{-2} \mathrm{~s}^{-1}$, en las que tanto la disminución de pigmento como la de nutrientes fue mucho menor, para el resto de tratamiento el valor del coeficiente $r^{2}>0.95$ (tabla 1 ).

Dinámica de nutrientes

Como se observa en la figura $2 \mathrm{c}, \mathrm{d}$ la disminución de la concentración de nutrientes en el medio a lo largo del tiempo se desarrolló en dos fases consecutivas. Una primera que
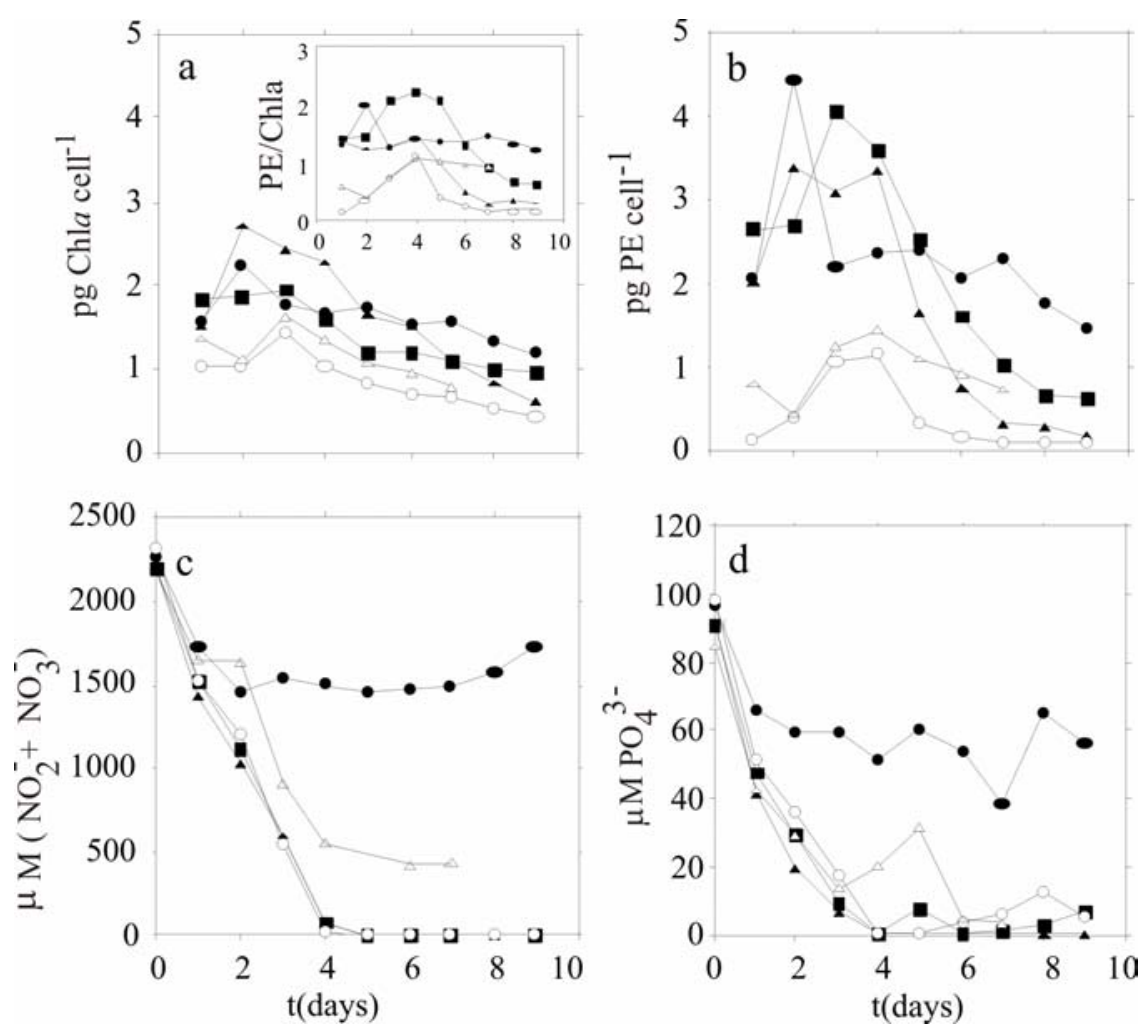

Figure 2. Time course of variation (culture age in days) in cellular chlorophyll a (a), cellular phycoerythrin content (b) and inorganic nitrogen (c) and phosphate (d) concentration in the culture medium for $R$. salina acclimated to $11(\bullet), 33(\mathbf{\Delta}), 75(\mathbf{\bullet}), 260(\mathrm{o})$ and $320(\triangle) \mu \mathrm{mol}$ photon $\mathrm{m}^{-2} \mathrm{~s}^{-1}$.

Figura 2. Evolución temporal del contenido celular de clorofila a (a), contenido celular de ficoeritrina (b), concentración de nitrógeno inorgánico en el medio (c) y concentración de fosfato en el medio (d) de cultivos de $R$. salina aclimatados a $11(\bullet), 33(\mathbf{\Delta}), 75(\mathbf{\bullet}), 260(\mathrm{o})$ and $320(\triangle) \mu \mathrm{mol}$ photon $\mathrm{m}^{-2} \mathrm{~s}^{-1}$. 
was characterized by a rapid nutrient uptake rate during the first 4 days after the nutrient addition, dropping to a lower and fairly constant uptake rate from this day until the end of the experimental time course. Nitrogen in the medium reached stable concentrations at $11 \mu \mathrm{mol}$ photon $\mathrm{m}^{-2} \mathrm{~s}^{-1}$ and $320 \mu \mathrm{mol}$ photon $\mathrm{m}^{-2} \mathrm{~s}^{-1}$ at day 2 and day 4 of growth, respectively, while phosphate concentrations showed varying but low levels and were only totally exhausted at $33 \mu \mathrm{mol}$ photon $\mathrm{m}^{-2} \mathrm{~s}^{-1}$ (fig. 2c, d). The N:P ratio in the water decreased in cultures grown at 33,75 and $260 \mu \mathrm{mol}$ photon $\mathrm{m}^{-2} \mathrm{~s}^{-1}$ while it increased in cultures grown under $11 \mu \mathrm{mol}$ photon $\mathrm{m}^{-2} \mathrm{~s}^{-1}$ and $320 \mu \mathrm{mol}$ photon $\mathrm{m}^{-2} \mathrm{~s}^{-1}$ (30\% and $75 \%$ respectively).

\section{P-I curves}

Figure 3 shows the P-I curves $(n=3)$ of $R$. salina grown under different incident irradiances expressed on a chlorophyll $a$ basis. The trend of the P-I curves expressed on a cell basis was equivalent (data not shown). The cell-specific and chlorophyll $a$-specific light-saturated net photosynthesis rates $\left(P_{\text {maxcell }}\right.$ and $\left.P_{\text {maxchla }}\right)$ were higher in lower-light adapted cells (11 and $75 \mu \mathrm{mol}$ photon $\mathrm{m}^{-2} \mathrm{~s}^{-1}$ ) compared with cells grown at the highest irradiance (table 2). $P_{\text {maxchla }}$ was maximum for cells grown under $75 \mu \mathrm{mol}$ photon $\mathrm{m}^{-2} \mathrm{~s}^{-1}$. The increase in photosynthetic pigments under lower light conditions (fig. 2a, b) also increased the efficiency of the cell to capture photons for photosynthesis under lower incident irradiances. This is reflected by the higher values of the initial slope obtained for

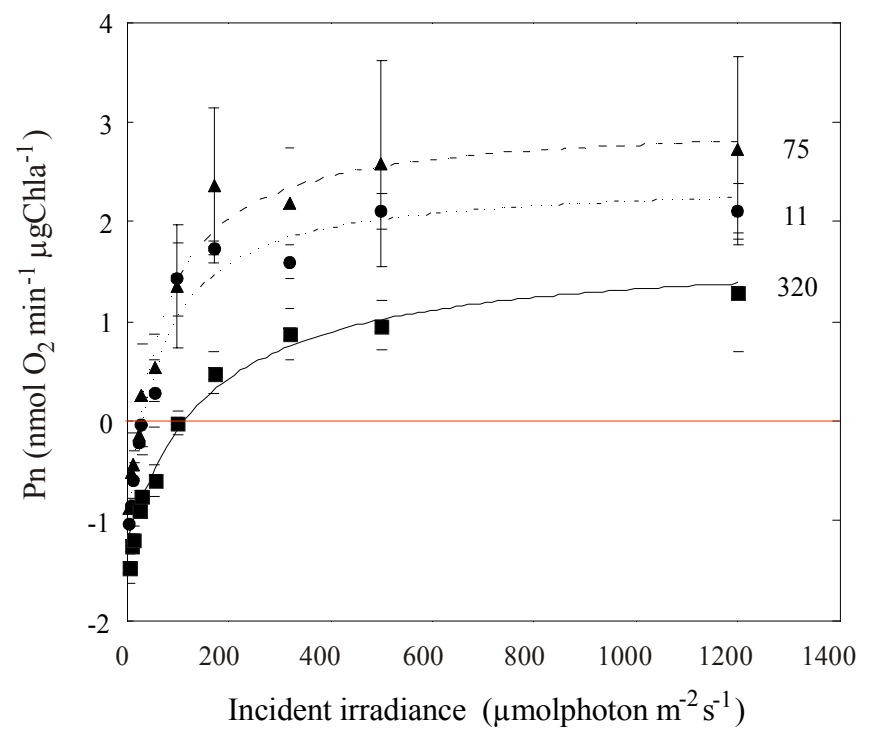

Figure 3. Photosynthesis vs irradiance (P-I) curve expressed by chlorophyll $a$ of $R$. salina acclimated to different incident irradiances (mean \pm s.d.; $n=3$ ). Symbols: $11(\bullet), 33(\mathbf{\Delta}), 75(\bullet), 260(\circ)$ and $320(\triangle) \mu$ mol photon $\mathrm{m}^{-2} \mathrm{~s}^{-1}$. Figura 3. Curvas fotosíntesis vs irradiancia $(P-I)$ (media \pm d.s.; $n=3$ ) expresadas por unidad de clorofila a de $R$. salina aclimatada a diferentes irradiancias incidentes. Símbolos: 11 (•), 33 (ム), 75 (•), 260 (o) and 320 $(\triangle) \mu \mathrm{mol}$ photon $\mathrm{m}^{-2} \mathrm{~s}^{-1}$.
Table 1. Parameters for the model of $P E$ decrease over time $P E=$ $\mathrm{PE}_{0} \times \mathrm{e}^{-\left[K_{\mathrm{PE}}\left(t-t_{i}\right)\right]}$ for each irradiance. $\mathrm{PE}=$ phycoerythrin content, $\mathrm{PE}_{0}=$ theoretical PE content at time $\left(t-t_{i}\right)=0, t_{i}=$ initial time period with no exponential decrease.

Tabla 1. Parametros para el modelo de decremento de PE con el tiempo $\mathrm{PE}=\mathrm{PE}_{0} \times \mathrm{e}^{-\left[K_{\mathrm{PE}}\left(t-t_{i}\right)\right]}$ para cada irradiancia. $\mathrm{PE}=$ contenido de ficoeritrina, $\mathrm{PE}_{0}=$ contenido teórico de $\mathrm{PE}$ al tiempo $\left(t-t_{i}\right)=0, t_{i}=$ tiempo inicial del periodo sin decremento exponencial.

\begin{tabular}{cccc}
\hline $\begin{array}{c}\text { Irradiance } \\
\left(\mu \mathrm{mol} \mathrm{photon}^{-2} \mathrm{~s}^{-1}\right)\end{array}$ & $\begin{array}{c}\mathrm{PE}_{0} \\
\left(\mathrm{pg} \mathrm{cell}^{-1}\right)\end{array}$ & $\begin{array}{c}K_{\mathrm{PE}} \\
\left(\text { day }^{-1}\right)\end{array}$ & $r^{2}$ \\
\hline 11 & 3.58 & 0.13 & 0.64 \\
33 & 3.37 & 0.71 & 0.99 \\
75 & 4.33 & 0.38 & 0.96 \\
260 & 1.13 & 1.04 & 0.99 \\
320 & 1.42 & 0.23 & 0.99 \\
\hline
\end{tabular}

abarcó los primeros cuatro días de crecimiento del cultivo, caracterizada por una tasa rápida de incorporación de nutrientes, disminuyendo hasta una tasa de desaparición de nutrientes mucho menor y prácticamente constante, en una segunda fase que se extendió hasta el final del experimento. Por el contrario, la concentración de nitrógeno en el medio alcanzó un valor constante en los cultivos aclimatados a 11 $\mu$ mol fotón $\mathrm{m}^{-2} \mathrm{~s}^{-1}$ y $320 \mu \mathrm{mol}$ fotón $\mathrm{m}^{-2} \mathrm{~s}^{-1}$ en los días 2 y 4 de crecimiento, respectivamente, frente a la concentración de fosfato que mostró valores variables y bajos, y sólo se consumió totalmente en los cultivos adaptados a $33 \mu \mathrm{mol}$ fotón $\mathrm{m}^{-2} \mathrm{~s}^{-1}$ (fig. 2c, d). El cociente N:P en el medio decreció en los cultivos aclimatados a 33, 75 y $260 \mu$ mol fotón $\mathrm{m}^{-2} \mathrm{~s}^{-1}$, mientras que aumentó en los cultivos aclimatados a 11 y $320 \mu$ mol fotón $\mathrm{m}^{-2} \mathrm{~s}^{-1}$ (en un $30 \%$ y $75 \%$, respectivamente).

Curvas fotosíntesis-irradiancia (P-I)

La figura 3 muestra las curvas P-I $(\mathrm{n}=3)$, expresadas por unidad de clorofila $a$, de $R$. salina cultivada a diferentes irradiancias incidentes. La tendencia de las curvas P-I expresadas en unidades de células fue equivalente (datos no presentados). Las tasas máximas fotosintéticas expresadas por célula y por clorofila $\left(P_{\text {maxcel. }}\right.$ y $\left.P_{\text {maxcla }}\right)$ fueron mayores en las células aclimatadas a las menores irradiancias $(11$ y $75 \mu \mathrm{mol}$ fotón $\mathrm{m}^{-2} \mathrm{~s}^{-1}$ ) en comparación con las células aclimatadas a 320 $\mu$ mol fotón $\mathrm{m}^{-2} \mathrm{~s}^{-1}$ (tabla 2). $P_{\text {maxcla }}$ fue máxima para las células aclimatadas a $75 \mu \mathrm{mol}$ fotón $\mathrm{m}^{-2} \mathrm{~s}^{-1}$. El aumento de pigmentos fotosintéticos (fig. 2a, b) en bajas condiciones de luz aumentó la eficiencia fotosintética (tabla 2) y, en definitiva, la eficiencia en la captura de fotones para la fotosíntesis. La irradiancia subsaturante de $75 \mu \mathrm{mol}$ fotón $\mathrm{m}^{-2} \mathrm{~s}^{-1}$ es así, la irradiancia óptima fotosintética para esta especie, presentando los máximos valores de $P_{\max } \mathrm{y} \alpha$. 
Table 2. Maximum photosynthetic rate on a per cell $\left(P_{\max \text { cell }}: \mathrm{nmol} \mathrm{O}_{2} \mathrm{~h}^{-1} \times 10^{-6}\right.$ cell) or chlorophyll a basis $\left(P_{\max }\right.$ chla: $\left.\mathrm{nmol}_{2} \mathrm{O}_{2} \mathrm{~min}^{-1} \mu \mathrm{gChla}{ }^{-1}\right)$ and initial slope on a cell $\left(\alpha\right.$ cell: $\mathrm{nmol} \mathrm{O}_{2} \mathrm{~h}^{-1} \times 10^{-6}$ cell $/ \mu \mathrm{mol}$ photon $\left.\mathrm{m}^{-2} \mathrm{~s}^{-1}\right)$ or cholophyll a basis $\left(\alpha_{\text {chla }}: \mathrm{nmol} \mathrm{O}_{2} \mathrm{~min}^{-1} \mu \mathrm{gChla} \mathrm{C}^{-1} / \mu \mathrm{mol}\right.$ photon $\left.\mathrm{m}^{-2} \mathrm{~s}^{-1}\right)$ of P-I curves of Rhodomonas salina. Data are expressed as mean $\pm \mathrm{s}$.d. of triplicate P-I curves.

Tabla 2. Tasas de fotosíntesis máxima por célula $\left(P_{\max }\right.$ cell $\left.\mathrm{nmol}_{2} \mathrm{~h}^{-1} \times 10^{-6} \mathrm{cel}\right)$ o por clorofila $a\left(P_{\text {max chla: }}: \mathrm{nmol}_{2} \mathrm{~min}^{-1} \mu \mathrm{gChla}{ }^{-1}\right)$ y pendiente inicial por célula ( $\alpha$ cel: $\mathrm{nmol} \mathrm{O} \mathrm{h}^{-1} 10^{-6} \mathrm{cel} / \mu \mathrm{mol}$ photon $\left.\mathrm{m}^{-2} \mathrm{~s}^{-1}\right)$ o por clorofila a $\left(\alpha_{\text {chla }}\right.$ : $\mathrm{nmol} \mathrm{O}_{2} \mathrm{~min}^{-1} \mu \mathrm{gChla}^{-1} / \mu \mathrm{mol}$ fotón $\left.\mathrm{m}^{-2} \mathrm{~s}^{-1}\right)$ de las curvas P-I de Rhodomonas salina. Los datos están expresados como el promedio \pm la desviación estándard de curvas P-I por triplicado.

\begin{tabular}{ccccc}
\hline Irradiance & $P_{\text {max cell }}$ & $P_{\text {max chla }}$ & $\alpha_{\text {cell }}$ & $\alpha_{\text {chla }}$ \\
\hline 11 & $206.5 \pm 20.5$ & $2.22 \pm 0.25$ & $3.96 \pm 0.86$ & $0.042 \pm 0.008$ \\
75 & $267.2 \pm 67.1$ & $2.71 \pm 0.95$ & $4.60 \pm 1.25$ & $0.045 \pm 0.015$ \\
320 & $102.5 \pm 45.4$ & $1.30 \pm 0.59$ & $2.30 \pm 0.67$ & $0.029 \pm 0.001$ \\
\hline
\end{tabular}

lower irradiances (table 2). The sub-saturated growth irradiance used $\left(75 \mu \mathrm{mol}\right.$ photon $\left.\mathrm{m}^{-2} \mathrm{~s}^{-1}\right)$ has shown to be the optimal irradiance for photosynthesis in this species, with the highest $P_{\max }$ and $\alpha$ values.

\section{Discussion}

Growth

Several cryptophyte genera, such as Chroomonas (Bowen, 1979), Cryptomonas (Thinh, 1983; 1988) and Pyrenomonas salina strain 3C (synonym $=$ Rhodomonas salina) (Lewitus and Caron, 1990), have been shown to achieve maximum growth rates at near $100 \mu \mathrm{mol}$ photon $\mathrm{m}^{-2} \mathrm{~s}^{-1}$. In the strain we have used, the relationship between growth rate and irradiance followed the same behaviour as strain $3 \mathrm{C}$, with a maximum from 75 to $260 \mu \mathrm{mol}$ photon $\mathrm{m}^{-2} \mathrm{~s}^{-1}$ (fig. 1). However, the maximum growth rate was somehow lower $\left(\sim 0.8 \mathrm{~d}^{-1}\right)$ than that obtained for strain $3 \mathrm{C}\left(1.2 \mathrm{~d}^{-1}\right)$ probably associated to speciesor strain-specific differences or temperature conditions, which were also different. The value of $\mu_{\max }$ fits well with the growth-irradiance relationship observed for Cryptomonas strain Lis (Thinh, 1988). This optimal range of growth irradiances coincides with the range of light levels used for mass cultures of this genus of microalgae in aquaculture (FernándezReiriz et al., 1989).

Photosynthetic pigments and nutrients

It has been demonstrated in many microalgae groups that nutrient deprivation causes a decrease in the pigment content and the photosynthetic rate, the cyanobacteria and red algae being the most studied groups (Boussiba and Richmond, 1980; Yamanaka and Glazer, 1980; Stevens et al., 1981; Köst et al., 1984). Thus, in cyanobacteria, a decrease in phycobilins has been observed under nutrient depletion conditions, increasing again if more nitrogen is made available (Allen and Smith, 1969). De novo synthesis of phycocyanin was shown to be depressed by nitrogen deficiency in Anacystis nidulans (Lau et al., 1977). In this alga, there is a degradation of phycobiliproteins already present in the organism when the cells are nitrogen-depleted (Yamanaka and Glazer, 1980). The nitrogen

\section{Discusión}

Crecimiento

Diversos géneros de criptofitas, como Chroomonas (Bowen, 1979), Cryptomonas (Thinh, 1983; 1988) y Pyrenomonas salina cepa 3C (sinónimo $=$ Rhodomonas salina) (Lewitus y Caron, 1990), han alcanzado tasas máximas de crecimiento en torno a $100 \mu \mathrm{mol}$ fotón $\mathrm{m}^{-2} \mathrm{~s}^{-1}$. En la cepa usada en este trabajo, la relación entre tasa de crecimiento e irradiancia siguió el mismo comportamiento que la cepa $3 \mathrm{C}$, con registros máximos situados entre 75 y $260 \mu \mathrm{mol}$ fotón $\mathrm{m}^{-2} \mathrm{~s}^{-1}$ (fig. 1). Sin embargo, la tasa máxima de crecimiento fue algo menor $\left(\sim 0.8 \mathrm{~d}^{-1}\right)$ que la obtenida para la cepa $3 \mathrm{C}\left(1.2 \mathrm{~d}^{-1}\right)$ probablemente debido a diferencias específicas de la cepa, o a diferentes condiciones de temperatura, ya que en el trabajo de Lewitus y Caron (1990) la temperatura empleada en los cultivos fue algo mayor $\left(21^{\circ} \mathrm{C}\right)$. El valor de $\mu_{\max }$ se ajusta bien a la relación crecimiento-irradiancia observada en Cryptomonas cepa Lis (Thinh, 1988). El rango óptimo de irradiancias de crecimiento obtenido en este trabajo coincide con el rango de intensidades lumínicas usadas para cultivos en masa de especies de este género en acuicultura (Fernández-Reiriz et al., 1989).

Pigmentos fotosintéticos y nutrientes

Se ha demostrado en muchos grupos algales, especialmente en cianobacterias y algas rojas, que el agotamiento de nutrientes provoca un descenso en el contenido pigmentario y en la tasa de fotosíntesis (Boussiba y Richmond, 1980; Yamanaka y Glazer, 1980; Stevens et al., 1981; Köst et al., 1984). Así, en condiciones de limitación de nutrientes, en cianobacterias se ha observado un descenso en la concentración de ficobilinas que de nuevo se recuperaba si se suministraba nitrógeno (Allen y Smith, 1969). En Anacystis nidulans se ha demostrado que la síntesis de novo de ficocianina se ve considerablemente disminuida debido a la deficiencia en la disponibilidad de nitrógeno (Lau et al., 1977) produciéndose, además, una degradación de las ficobiliproteínas celulares ya existentes bajo condiciones de limitación por nitrógeno (Yamanaka y Glazer, 1980). Este pigmento probablemente actúa en determinadas situaciones como reservorio de nitrógeno que se moviliza de las ficobiliproteínas permitiendo el crecimiento celular. 
present in the phycobiliproteins is mobilized to support cell growth, with this pigment probably acting as a nitrogen reservoir in some cases. In Cryptophyceae, this was first reported by Lichtlé (1979) who studied this effect in Cryptomonas rufescens. Later, Rhiel et al. (1985) observed the loss of $90 \%$ of the phycoerythrin content in a period of 10-14 days in Cryptomonas maculata under nitrogen depletion conditions. The hypothesis that PE may act as an internal nitrogen source is also supported for the cryptophyte Pyrenomonas salina (Lewitus and Caron, 1990). These authors demonstrated that PE cell content decreased dramatically during the stationary growth phase of nitrogen-depleted cultures. However, the precise time of nitrogen exhaustion and the relationship between inorganic nitrogen availability besides the extent of the PE decrease were not established. Our work contributes to an estimation of the extent PE decrease under different irradiances and external nitrogen availability in dense cultures, having into account that, under saturated $\left(320 \mu \mathrm{mol}\right.$ photon $\left.\mathrm{m}^{-2} \mathrm{~s}^{-1}\right)$ and limited $\left(11 \mu \mathrm{mol}\right.$ photon $\left.\mathrm{m}^{-2} \mathrm{~s}^{-1}\right)$ light conditions, nutrients were never exhausted.To discuss such PE mobilization, the decrease rates of cellular PE were estimated $\left(K_{\mathrm{PE}}\right.$; see equation 1). The values of $K_{\mathrm{PE}}$ ranged from 0.13 to $1.04 \mathrm{~d}^{-1}$ (table 1).

The decrease rates of cellular PE $\left(K_{\mathrm{PE}}\right)$ vs average $\mathrm{NO}_{2}{ }^{-}+$ $\left.\mathrm{NO}_{3}^{-}\right]$in the medium during the phase of PE decline (fig. 4) follow a negative exponential trend. This relationship supports the hypothesis that inorganic nitrogen availability is the most important factor controlling the dynamics of the PE degradation. As it is observed in figure 4, cells grown at 11 and 320 $\mu$ mol photon $\mathrm{m}^{-2} \mathrm{~s}^{-1}$ showed similar values of $K_{\mathrm{PE}}$, not dependending on the inorganic nitrogen concentration. In these

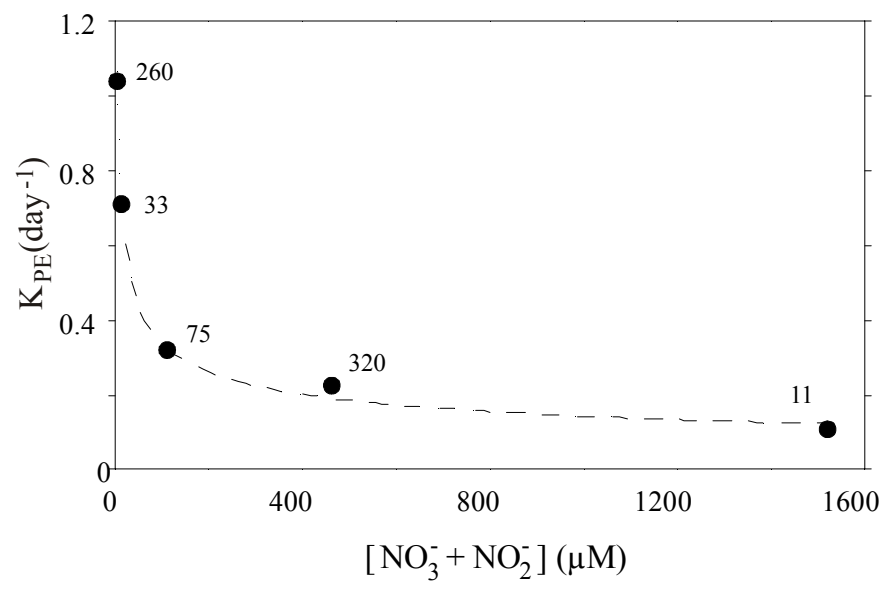

Figure 4. Relationship between the decrease rate of cellular PE ( $\left.K_{\mathrm{PE}}\right)$ and average $\left[\mathrm{NO}_{3}{ }^{-}+\mathrm{NO}_{2}\right]$ concentrations in cultures of $R$. salina grown at different incident irradiances (11 (•), $33(\mathbf{\Delta}), 75(\bullet), 260$ (০) and $320(\triangle)$ umol photon $\mathrm{m}^{-2} \mathrm{~s}^{-1}$ ).

Figura 4. Relación entre la tasa de disminución de PE celular ( $\left.\mathrm{K}_{\mathrm{PE}}\right)$ y $\left[\mathrm{NO}_{3}{ }^{-}\right.$ $+\mathrm{NO}_{2}^{-}$] promedio en cultivos de $R$. salina aclimatados a diferentes irradiancias incidentes. Símbolos: (11 (•), 33 (A), 75 (•), 260 (о) and 320 $(\triangle) \mu \mathrm{mol}$ photon $\mathrm{m}^{-2} \mathrm{~s}^{-1}$ ).
En la clase Cryptophyceae, el primer estudio que describe el posible papel de reservorio de nitrógeno de las ficobiliproteínas fue realizado por Lichtlé (1979) en Cryptomonas rufescens. Posteriormente, Rhiel et al. (1985) observaron una pérdida del $90 \%$ del contenido de ficoeritrina a lo largo de 10 14 días en condiciones de limitación de nitrógeno en Cryptomonas maculata. La hipótesis de que la PE pueda actuar como fuente interna de nitrógeno también se verificó para la criptofita Pyrenomonas salina (Lewitus y Caron, 1990). Estos autores demostraron que el contenido celular de PE disminuyó fuertemente ante una limitación de nitrógeno durante la fase estacionaria de crecimiento. Sin embargo no se estableció el momento preciso de dicha limitación ni la relación entre la disponibilidad de nitrógeno inorgánico y la magnitud del descenso de PE. Nuestro trabajo contribuye a estimar la intensidad del descenso en la cantidad de PE en diferentes condiciones de irradiancia y disponibilidad de nitrógeno externo en cultivos densos, incluyendo situaciones de luz saturante $(320 \mu \mathrm{mol}$ fotón $\left.\mathrm{m}^{-2} \mathrm{~s}^{-1}\right)$ y limitante $\left(11 \mu \mathrm{mol}\right.$ fotón $\left.\mathrm{m}^{-2} \mathrm{~s}^{-1}\right)$ en las que no hubo agotamiento de nutrientes. Con el fin de discutir la movilización de PE se estimaron sus correspondientes tasas de desaparición celular ( $K_{\mathrm{PE}}$; ver ecuación 1$)$. Los valores de $K_{\mathrm{PE}}$ oscilaron entre 0.13 y $1.04 \mathrm{~d}^{-1}$ (tabla 1 ).

Las tasas de desaparición celular de PE $\left(K_{\mathrm{PE}}\right)$ vs $\left[\mathrm{NO}_{2}{ }^{-}+\right.$ $\mathrm{NO}_{3}{ }^{-}$] durante la fase de descenso de la concentración de PE (fig. 4) sigue una tendencia exponencial negativa. Esta relación apoya la hipótesis de que la disponibilidad de nitrógeno inorgánico es el factor más importante en el control de la dinámica de degradación de PE. Como se observa en la figura 4, las células cultivadas a 11 y $320 \mu \mathrm{mol}$ fotón $\mathrm{m}^{-2} \mathrm{~s}^{-1}$ registraron valores similares de $K_{\mathrm{PE}}$, e independientes de la concentración de nitrógeno inorgánico. Estos cultivos no estuvieron en ningún momento limitados por nitrógeno (fig. 2c) por lo que la reducción en el contenido de PE por célula (fig. $2 \mathrm{~b}$ ) es atribuíble en mayor medida al efecto de dilución por división celular que a la movilización de PE por estrés nutricional. En este estudio, el agotamiento de nitrógeno se produce de manera paralela al de fosfato. El efecto individualizado de cada nutriente no puede discernirse, aunque se ha demostrado para $P$. salina, y se considera una respuesta general, que el descenso en la concentración de PE celular, en cultivos limitados por fósforo, se produce a una tasa muy inferior respecto a los limitados por nitrógeno (Lewitus y Caron, 1990).

La degradación de ficoeritrina se considera un mecanismo movilizador de nitrógeno que permite el crecimiento y/o el mantenimiento celular cuando dicho nutriente es limitante. Excepto para los tratamientos de luz incidente correspondientes a 11 y $320 \mu \mathrm{mol}$ fotón $\mathrm{m}^{-2} \mathrm{~s}^{-1}$, el final de la fase exponencial de crecimiento coincide con el inicio del agotamiento de nutrientes (fig. 2c, d). A estas irradiancias (33, 75 y $260 \mu \mathrm{mol}$ fotón $\mathrm{m}^{-2} \mathrm{~s}^{-1}$ ) el cultivo no detiene su crecimiento, aunque la pendiente de la curva en la fase final de experimentación (en la denominada fase estacionaria de crecimiento) se reduce considerablemente. Dicha pendiente $(\gamma)$ se ha calculado para 
cultures, cells were never under nitrogen limitation (fig. 2c) and so, the reduction in the PE content, expresed by cell (fig. $2 b$ ), is more associated to the dilution factor caused by cell division than to a PE mobilization under nutrient stress. In this study, the depletion of nitrogen is parallel to that of phosphate. The individual effect of each nutrient cannot be discerned, but for $P$. salina it was demonstrated that the decrease in PE concentration per cell in phosphorus-depleted cultures occurred at a much slower rate than that in nitrogen-depleted cultures (Lewitus and Caron, 1990), and this is explained as a general response to nutrient deprivation.

The phycoerythrin degradation is believed to be a mechanism for mobilizing nitrogen to sustain cellular growth and/or maintenance when this nutrient is in short supply. The end of the exponential growth phase coincides with the beginning of nutrient-depletion conditions (fig. 2c,d) at all the irradiances used, apart from the 11 and $320 \mu \mathrm{mol}$ photon $\mathrm{m}^{-2} \mathrm{~s}^{-1}$ light levels. At these irradiances $\left(33,75\right.$ and $260 \mu \mathrm{mol}$ photon $\left.\mathrm{m}^{-2} \mathrm{~s}^{-1}\right)$ cells do not stop growing but the slope of the growth curve at the end of the experimental data (in the so-called stationary growth phase) is clearly reduced. This slope $(\gamma)$ has been calculated for all the irradiances and it is significantly higher in cells grown under 11 and $320 \mu \mathrm{mol}$ photon $\mathrm{m}^{-2} \mathrm{~s}^{-1}$, which have the lowest $K_{\mathrm{PE}}$ values and the external nutrients were not depleted. Therefore, two different growth responses can be distinguised in the second phase above mentioned (fig. 5). Firstly, cultures (11 and $320 \mu \mathrm{mol}$ photon $\mathrm{m}^{-2} \mathrm{~s}^{-1}$ ) with relatively high $\gamma$, supported by external nutrients and scarce or no use of nitrogen originating from $\mathrm{PE}$ degradation (low $K_{\mathrm{PE}}$; treatments over the 1:1 line in fig. 5) and, secondly, cultures that have a low $\gamma$ (33, 75 and $260 \mu \mathrm{mol}$ photon $\mathrm{m}^{-2} \mathrm{~s}^{-1}$ ) with very low concentrations of external nutrients, but sustained by high rates of $\mathrm{PE}$ decrease (high $K_{\mathrm{PE}}$; treatments under the 1:1 line in fig. 5). In this case, it can be suggested that most of the nitrogen from PE sustains metabolism together with very low growth rates.

Photosynthetic pigments and light

The response of the phytoplankton to irrandiance variations has been studied extensively and, in general, this is correlated with variations in the pigment content with higher concentrations at lower light levels (Jørgensen, 1969; 1970; Rivkin et al., 1982; Falkowski and Laroche, 1991 and others). The response observed in R. salina is similar to that observed in other species of cryptophytes (Brown and Richardson, 1968; Faust and Gantt, 1973; Lichtlé et al., 1986). Thinh (1983) observed that the chlorophyll content of Cryptomonas (strain Lis) cells acclimated to $10 \mu \mathrm{mol}$ photon $\mathrm{m}^{-2} \mathrm{~s}^{-1}$ was twice as much as that of cells grown at $260 \mu \mathrm{mol}$ photon $\mathrm{m}^{-2} \mathrm{~s}^{-1}$, in agreement with the results obtained for $R$. salina. This increasing chlorophyll $a$ content along with decreasing light irradiance has been observed by Gervais (1997) in different strains of freshwater Cryptomonas acclimated to irradiances between 30 and 90 todos los tratamientos, siendo significativamente más alta en los cultivos aclimatados a 11 y $320 \mu \mathrm{mol}$ fotón $\mathrm{m}^{-2} \mathrm{~s}^{-1}$, que a su vez presentan los valores más bajos de $K_{\mathrm{PE}} \mathrm{y}$ disponibilidad de nutrientes. Por tanto, pueden distinguirse dos respuestas diferentes de crecimiento en la etapa enunciada anteriormente como estacionaria (fig. 5). En primer lugar, la de los cultivos (11 y $320 \mu$ mol fotón $\mathrm{m}^{-2} \mathrm{~s}^{-1}$ ) con un valor relativamente elevado de $\gamma$, mantenido por nutrientes externos y nulo o escaso uso de nitrógeno procedente de la degradación de PE (baja $K_{\mathrm{PE}}$; tratamientos por encima de la línea 1:1 en la figura 5); en segundo lugar, la de los cultivos (33, 75 y $260 \mu \mathrm{mol}$ fotón $\mathrm{m}^{-2} \mathrm{~s}^{-1}$ ) con un valor bajo de $\gamma$, aunque mantenidos por altas tasas de desaparición de PE, ya que los nutrientes externos presentan muy baja concentración (alta $\mathrm{K}_{\mathrm{PE}}$; tratamientos por debajo de la línea 1:1 en la figura 5). En este último caso se puede sugerir que el nitrógeno movilizado, procedente de la $\mathrm{PE}$, permite el mantenimiento del metabolismo junto con tasas de crecimiento muy bajas.

Pigmentos fotosintéticos y luz

La respuesta del fitoplancton a cambios en la irradiancia se ha estudiado ampliamente y, en general, se relaciona con incrementos en el contenido pigmentario a bajas intensidades lumínicas (Jørgensen, 1969, 1970; Rivkin et al., 1982; Falkowski y Laroche, 1991 y otros). La respuesta observada en $R$. salina es similar a la registrada en otras especies de criptofitas (Brown y Richardson, 1968; Faust y Gantt, 1973; Lichtlé et al., 1986). Thinh (1983) observó que el contenido celular de clorofila de

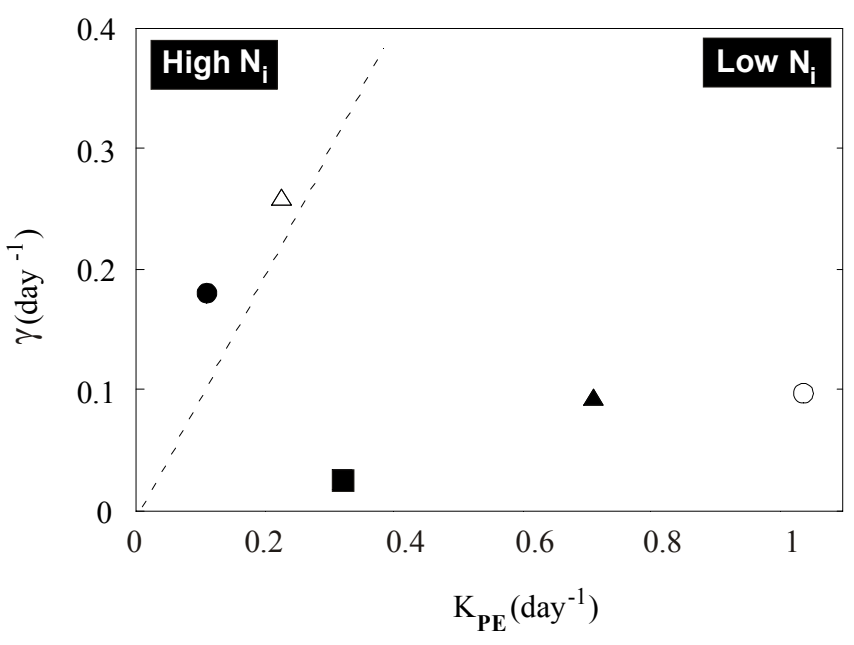

Figure 5. Relationship between decrease rate of cellular PE $\left(K_{\mathrm{PE}}\right)$ and growth rate after day five of growth $(\gamma)$ of cultures of $R$. salina grown at 11 $(\bullet), 33(\mathbf{\Delta}), 75(\mathbf{\bullet}), 260(\circ)$ and $320(\triangle) \mu \mathrm{mol}$ photon $\mathrm{m}^{-2} \mathrm{~s}^{-1}$. The dashed line indicates a 1:1 relationship between both parameters. $\mathrm{Ni}=$ external nitrogen concentration.

Figura 5. Relación entre la tasa de disminución de PE celular $\left(K_{\mathrm{PE}}\right)$ y la tasa de crecimiento a partir del día 5 de crecimiento $(\gamma)$ en cultivos de $R$. salina aclimatados a $11(\bullet), 33(\mathbf{\Delta}), 75(\bullet), 260(\mathrm{o})$ and $320(\triangle) \mu \mathrm{mol}$ photon $\mathrm{m}^{-2} \mathrm{~s}^{-1}$. La línea punteada indica una relación $1: 1$ entre ambos parámetros. Ni: concentración de nitrógeno externo. 
$\mu$ mol photon $\mathrm{m}^{-2} \mathrm{~s}^{-1}$. In our study, $R$. salina was grown under the full range of irradiances used by these authors. Cells acclimated to lower irradiances $\left(11,33\right.$ and $75 \mu \mathrm{mol}$ photon $\mathrm{m}^{-2} \mathrm{~s}^{-}$ 1) had higher chlorophyll $(a+c)$ content than cells grown at higher irradiances (260 and $320 \mu \mathrm{mol}$ photon $\mathrm{m}^{-2} \mathrm{~s}^{-1}$ ). However, it was also observed that the cells acclimated to the lowest irradiance $\left(11 \mu \mathrm{mol}\right.$ photon $\left.\mathrm{m}^{-2} \mathrm{~s}^{-1}\right)$ did not have the maximum pigment content possibly because the low incident irradiances decreased the pigment synthesis (fig. 2) and the photosynthetic activity (fig. 4). The response of chlorophyll $c$ to irradiance is variable among this group of microalgae. Our results did not show significant alteration of chlorophyll $c$ content with irradiance ( $t$-test, $P<0.05)$ in agreement with the results obtained by Lewitus et al. (1991). Conversely, Thinh (1983) observed an inverse relationship between chlorophyll $c$ content and irradiance at two extreme irradiances, 10 and 260 $\mu \mathrm{mol}$ photon $\mathrm{m}^{-2} \mathrm{~s}^{-1}$. It is probable that the latter irradiance was photo-inhibitory, an effect that has been observed in a number of microalgae (Perry et al., 1981).

\section{P-I curves}

Rhodomonas salina displayed higher $P_{\max }$ and $\alpha$ values at lower irradiances than under higher ones, in agreement with the study of Thinh (1983) on Cryptomonas strain Lis. The same trend has been recorded in the diatom Ditylum brightwelli Westt (Perry et al., 1981) and the dinoflagellate Peridinium cinctum (O. F. Müller, Ehrenberg, 1832) (Prézelin and Sweeney, 1979). The $P_{\max }$ acclimated to $75 \mu \mathrm{mol}$ photon $\mathrm{m}^{-2} \mathrm{~s}^{-1}$ was higher than the values at any other irradiance, when it is expressed per chlorophyll $a$. At this light intensity, cells show the maximum $\mathrm{PE} / \mathrm{Chl} a$ ratio which may indicate the importance of the antennae of phycobiliproteins in the photosynthetic activity of this species. The P-I curves obtained for $R$. salina did not fit any of the models described by Prézelin (1981). Based on the review by Richardson et al. (1983) regarding photoadaptative strategies in unicellular algae, the P-I curves obtained suggest that $R$. salina adapts to lower irradiances by increasing its number of PSUs. These authors include in this type of response cells not adapted to low irradiance but stressed by the increasing irradiance conditions. The ultrastructural studies on photoadaptation in Crypthophyceae describe a disorganization of the thylakoids, conservation of the number of PSUs and alterations in the PSII antenna size (Rhiel et al., 1985; Lichtlé et al., 1986; Lewitus et al., 1991) as a main adaptation mechanism. This is in agreement with the lower content of pigment, mainly PE, observed for $R$. salina. Scanning electron microscopy and cryofracture analysis showed that $P$. salina responded to a high irradiance with a loss of PSII antennae and disorganization of the thylakoid structure (Lewitus et al., 1991), although from a classical analysis of P-I curves, a different structural and functional adaptation strategy could be inferred.
Cryptomonas (cepa Lis) aclimatada a $10 \mu \mathrm{mol}$ fotón $\mathrm{m}^{-2} \mathrm{~s}^{-1}$ era el doble de las células cultivadas a $260 \mu \mathrm{mol}$ fotón $\mathrm{m}^{-2} \mathrm{~s}^{-1}$, en concordancia con los resultados obtenidos para $R$. salina. El incremento en el contenido de clorofila $a$ al disminuir la intensidad luminosa ha sido observado por Gervais (1997) en diferentes cepas de agua dulce de Cryptomonas aclimatadas a irradiancias entre 30 y $90 \mu \mathrm{mol}$ fotón $\mathrm{m}^{-2} \mathrm{~s}^{-1}$. En nuestro estudio, $R$. salina fue cultivada cubriendo el rango completo de irradiancias usadas por los anteriores autores. Las células aclimatadas a las irradiancias menores $(11,33$ y $75 \mu \mathrm{mol}$ fotón $\mathrm{m}^{-2} \mathrm{~s}^{-1}$ ) registraron un mayor contenido de clorofila $(a+c)$ que las cultivadas a mayores intensidades luminosas (260 y $320 \mu \mathrm{mol}$ fotón $\left.\mathrm{m}^{-2} \mathrm{~s}^{-1}\right)$. Sin embargo, tambien se observó que las células aclimatadas al tratamiento de menor irradiancia (11 $\mu \mathrm{mol}$ fotón $\mathrm{m}^{-2} \mathrm{~s}^{-1}$ ) no presentaron el máximo contenido pigmentario, probablemente porque la baja irradiancia incidente redujo la síntesis pigmentaria (fig. 2) así como la actividad fotosintética (fig. 4). La respuesta de la clorofila $c$ a cambios en la intensidad luminosa es variable en este grupo algal. Nuestros resultados no muestran variaciones significativas del contenido de clorofila $c$ con la irradiancia ( $t$-test, $P<0.05$ ), en consonancia con los resultados obtenidos por Lewitus et al. (1991). Por el contrario, Thinh (1983) observó una relación inversa entre el contenido de clorofila $c$ y la irradiancia en dos tratamientos extremos, 10 y $260 \mu \mathrm{mol}$ fotón $\mathrm{m}^{-2} \mathrm{~s}^{-1}$. Es probable que esta última intensidad luminosa fuera fotoinhibitoria, efecto que ha sido observado en diversas microalgas (Perry et al., 1981).

\section{Curvas P-I}

Rhodomonas salina cultivada a bajas irradiancias registró valores superiores de $P_{\max }$ y $\alpha$ que las células aclimatadas a alta intensidad luminosa, coincidiendo estos resultados con el estudio de Thinh (1983) en Cryptomonas cepa Lis. La misma tendencia se ha observado en la diatomea Ditylum brightwelli Westt (Perry et al., 1981) y el dinoflagelado Peridinium cinctum (O.F. Müller, Ehrenberg, 1832) (Prézelin and Sweeney, 1979). El valor de $P_{\text {max }}$, expresado por clorofila $a$, de las células aclimatadas a $75 \mu \mathrm{mol}$ fotón $\mathrm{m}^{-2} \mathrm{~s}^{-1}$ fue el más alto de los registrados. A esta irradiancia las células presentaron el valor más alto de la relación PE/clorofila $a$, lo que podría indicar la importancia de la antena de ficobiliproteinas en la actividad fotosintética de esta especie. Las curvas P-I obtenidas para $R$. salina no se ajustan a ninguno de los modelos descritos por Prézelin (1981). De acuerdo con la revisión de Richardson et al. (1983) sobre estrategias fotoadaptativas en algas unicelulares, las curvas P-I obtenidas sugieren que $R$. salina se adapta a bajas irradiancias incrementando el número de PSUs. Estos autores incluyen en este grupo a células a las que el incremento de irradiancia les genera respuestas de estrés. Los estudios ultraestructurales realizados sobre foto-adaptación en la clase Crypthophyceae describen, como principales mecanismos 
In this analysis of photoadaptation strategies and interpretation of P-I curves, it is important to stick out the culture conditions used, that is, batch high-cell-density cultures, which may imply considerable light attenuation. The results obtained for $R$. salina are applicable to mass cultures of this alga but some considerations about incident light should be needed for a physiological understanding.

In summary, $R$. salina grows maximally at an irradiance range between 75 and $260 \mu \mathrm{mol}$ photon $\mathrm{m}^{-2} \mathrm{~s}^{-1}$. In this range, photoacclimation is characterized by an increase in the lightharvesting antennae size (PE content mainly) at decreasing irradiances, being the photosynthetic activity optimal at 75 $\mu \mathrm{mol}$ photon $\mathrm{m}^{-2} \mathrm{~s}^{-1}$. At irradiances over $300 \mu \mathrm{mol}$ photon $\mathrm{m}^{-2} \mathrm{~s}^{-1}$, growth is slightly inhibited and there is also a reduction in the photosynthetic activity. The time course of evolution of PE content and external nutrients in the medium show that $R$. salina responds to nitrogen-depleted conditions by mobilizing nitrogen from $\mathrm{PE}$, this behaviour being modelled by a relationship between external nitrogen availability and PE mobilization.

\section{Acknowledgments}

This work has been supported by a project of the CICYT (AMB-0684-CO2-01) from the Ministerio de Educación y Cultura, Spain.We thank J. L. Pérez-Lloréns, J. J. Vergara and J. Berges for their critical reviews and helpful comments during the preparation of this manuscript. We also thank three anonymous reviewers for the correction of a previous version of this work.

\section{References}

Allen, M.M. and Smith, A.J. (1969). Nitrogen Chlorosis in blue green algae. Arch. Microbiol., 69: 114-120.

Boussiba, S. and Richmond, A.E. (1980). C-phycocianin as a storage protein in the blue green alga Spirulina platensis. Arch. Microbiol., 125: 143-147.

Bowen, M.S. (1979). Laboratory culture of Cryptomonas ovata and Chroomonas sp. (Crypthophyceae). Microbios., 6: 77-94.

Brown, T.E. and Richardson, F.L. (1968). The effect of growth environment on the physiology of algae: light intensity. J. Phycol., 4: $38-54$.

Dodge, J.D. (1969). The ultrastructure of Chroomonas mesostigmatica Butcher (Cryptophyceae). Arch. Microbiol., 69: 266-280.

Eriksen, N.T. and Iversen, J.J.L. (1995). Photosynthetic pigments as nitrogen stores in the cryptophyte alga Rhodomonas sp. J. Mar. Biotechnol., 3: 193-195.

Eriksen, N.T., Geest, T. and Iversen, J.J.L. (1996). Phototrophic growth in the lumostat: a photo-bioreactor with on-line optimization of light intensity. J. Appl. Phycol., 8: 345-352.

Falkowski, P.G. and LaRoche, G. (1991). Acclimation of plankton algae. Variation in the photosynthetic characteristics of Skeletonema costatum cells grown at low light intensity. Physiol. Plantarum., 23: 11-17.

Faust, M.A. and Gantt, E. (1973). Effect of light intensity and glycerol on the growth, pigment composition and ultrastructure of Chroomonas sp. J. Phycol., 9: 489-495. adaptativos, desorganización de los tilacoides, conservación del número de PSUs y alteraciones en el tamaño de la antena del PSII (Rhiel et al., 1985; Lichtlé et al., 1986; Lewitus et al., 1991). Esta última estrategia propuesta estaría de acuerdo con el bajo contenido de pigmentos observado en la especie estudiada, especialmente el de ficoeritrina. Los estudios realizados con microscopía electrónica de barrido y criofractura muestran que $P$. salina respondió a tratamientos de alta irradiancia con pérdida de antena del PSII y desorganización de la estructura tilacoidal (Lewitus et al., 1991). Sin embargo, a partir de un análisis clásico de las curvas P-I, se inferiría una diferente estrategia adaptativa estructural y funcional.

En este análisis de estrategias fotoadaptativas e interpretación de curvas P-I, es importante insistir en las condiciones experimentales, es decir, cultivos de elevada densidad celular, lo que puede implicar una considerable atenuación luminosa. Los resultados obtenidos para $R$. salina son aplicables en cualquier caso a cultivos masivos del alga, no obstante, diversas consideraciones acerca de la luz incidente en dichos cultivos serían necesarias para una comprensión fisiológica.

En resumen, $R$. salina presenta tasas máximas de crecimiento en un rango de irradiancias entre 75 y $260 \mu \mathrm{mol}$ fotón $\mathrm{m}^{-2} \mathrm{~s}^{-1}$. En este rango, la fotoaclimatación a bajas irradiancias se caracteriza por un incremento en el tamaño de la antena recolectora de luz (principalmente ficoeritrina), con una actividad fotosintética óptima a $75 \mu \mathrm{mol}$ fotón $\mathrm{m}^{-2} \mathrm{~s}^{-1}$. A irradiancias por encima de $300 \mu \mathrm{mol}$ fotón $\mathrm{m}^{-2} \mathrm{~s}^{-1}$ el crecimiento sufre una ligera inhibición y la actividad fotosintética se reduce. La evolución temporal del contenido de PE y de nutrientes externos en el medio de cultivo demuestran que $R$. salina responde, en condiciones limitantes de nitrógeno, movilizando nitrógeno de la PE, comportamiento que se modela conceptualmente a partir de las relaciones entre la disponibilidad de nitrógeno externo y la tasa de desaparición celular de PE.

\section{Agradecimientos}

Este trabajo ha sido financiado por un proyecto CICYT (AMB-0684-CO2-01) del Ministerio de Educación y Cultura, España. Le agradecemos a J. L. Pérez-Lloréns, J. J. Vergara y J. Berges por las correcciones y útiles comentarios durante la preparación del presente manuscrito. Igualmente, le agradacemos a tres revisores anónimos las correcciones realizadas en la versión previa de este manuscrito.

Traducido al español por los autores.

Fernández-Reiriz, M.J., Pérez-Camacho, A., Ferreiro, M.J., Blanco, J., Planas M., Campos, J.M. and Labarta, U. (1989). Biomass production and variation on the biochemical profile (total protein, carbohydrates, RNA, lipids and fatty acids) of seven species of marine microalgae. Aquaculture, 83: 17-38.

Gervais, F. (1997). Light-dependent growth, dark survival, and glucose uptake by cryptophytes isolated from a freshwater chemocline. J. Phycol., 33: 18-25. 
Grasshoff, K., Ehrhardt, M. and Kremling, K. (1983). Methods of Seawater Analysis, 2nd edition. Verlag Chemie, Weinheim, Germany, 419 pp.

Grobbelaar, J.U., Nedbal, L. and Tichy, V. (1996). Influence of high frequency light/dark fluctuations on photosynthetic characteristics of microalgae photoacclimated to different light intensities and implications for mass algal cultivation. J. Appl. Phycol., 8: 335343.

Guillard, R.R.L. and Ryther, J.H. (1962). Studies on marine planktonic diatoms I. Cyclotella nana Husted and Detonula conforvacae Cleve. Gran. Can. J. Microbiol., 8: 229-239.

Henley, W.J. (1993). Measurement and interpretation of photosynthetic light-response curves in algae in the context of photoinhibition and diel changes. J. Phycol., 29: 729-739.

Hill, D.R.A. and Wetherbee, R. (1989). A reappraisal of the genus Rhodomonas (Cryptophyceae). Phycologia, 28: 143-158.

Jeffrey, S.W. and Haxo, F.T. (1968). Photosynthetic pigments of symbiotic dinoflagellates (zooxanthellae) from corals and clams. Biol. Bull., 135: 149-165.

Jørgensen, E.G. (1969). The adaptation of plankton algae. IV. Light adaptation of different algal species. Physiol. Plantarum, 22: $1307-1315$.

Jørgensen, E.G. (1970). The adaptation of plankton algae. V. Variation in the photosynthetic characteristics of Skeletonema costatum cells grown at low light intensity. Physiol. Plantarum, 23: 11-17.

Kitano, M., Matsukawa, R. and Karube, I. (1997). Changes in eicosapentaenoic acid content on Navicula saprophila, Rhodomonas salina and Nitzschia sp. under mixotrophic conditions. J. Appl. Phycol., 9: 559-563.

Köst. H.P., Senser, M., and Wanner, G. (1984). Effect of nitrate and sulphate starvation on Porphyridium cruentum cells. Z. Pflanzenphysiol., 113: 231-249.

Kurmaly K., Jones, D.A., Yule, A.B. and East J. (1989). Comparative analysis of the growth and survival of Peneaus monodon (Fabricius) larvae, from Protozoea 1 postlarva 1, on live feeds, artificial diets and combinations of both. Aquaculture, 81: 27-45.

Lau, R.H., Mackenzie, M.M. and Doolittle, W. F. (1977). Phycocyanin synthesis and degradation in the blue-green bacteria Anacystis nidulans. J. Bacteriol., 132: 771-778.

Lewitus, A.J. and Caron, D.A. (1990). Relative effects of nitrogenus or phosphorus depletion and light intensity on the pigmentation, chemical composition, and volume of Pyrenomonas salina (Cryptophyceae). Mar. Ecol. Prog. Ser., 61: 171-181.

Lewitus, A.J., Caron, D.A., and Miller, K.R. (1991). Effects of light and glycerol on the organization of the photosynthetic apparatus in the facultative heterotroph Pyrenomonas salina (Crypthophyceae). J. Phycol., 27: 578-587.

Lichtlé, C. (1979). Effects of nitrogen deficiency and light of high intensity on Cryptomonas rufescens (Cryptophyceae). I. Cell and photosyntetic apparatus transformations and encystment. Protoplasma, 101: 283-293.

Lichtlé, C., Duval, J.C., and Spilar, A. (1986). Freeze fracture study of thylakoid organization of Cryptomonas rufescens (Cryptophyceae) according to illumination conditions. Photobiochem. Photobiophys., 11: 159-171.

MacColl, R., Donald, S.B. and Gibbons, O. (1976). Characterization of cryptomonad phycoerythrin and phycocyanin. Arch. Biochem. Biophys. 177: 265-275.
Ojala, A. (1993). Effects of temperature and irradiance on the growth of two freshwater photosynthetic cryptophytes. J. Phycol., 29: 278-284.

Perry, M.J., Talbot M.C., and Alberte, S. (1981). Photoadaptation in Marine Phytoplankton: Response of the Photosynthetic Unit. Mar. Biol., 62: 91-101.

Prézelin, B.B. (1981). Light reactions in photosynthesis. In: Physiological Bases of Phytoplankton Ecology (Trevor Platt, editor) Can. Bull. Fish. Aquat. Sci., 1-43.

Prézelin, B.B. and Sweeney, B.M. (1979). Photoadaptation of photosynthesis in two bloom-forming dinoflagellates. In: D. Taylor and H. Seliger (eds.), Toxics Dinoflagellates Blooms. Elsevier, North Holland, pp. 101-106.

Renaud, S.M., Thinh, L-V., Lambrinidis, G. and Parry, D.L. (2002). Effects of temperature on growth, biochemical composition and fatty acid composition of tropical Australian microalgae grown in batch culture. Aquaculture, 211(1-4): 195-214.

Rhiel, E., Morschel E., and Wehrmeyer, W. (1985). Correlation of pigment deprivation and ultraestructural organization of thylakoid membranes in Cryptomonas maculata following nutrient defficiency. Protoplasma, 129: 62-73.

Richardson, K., Beardall, J., and Raven, J.A. (1983). Adaptation of unicellular algae to irradiance: an analysis of strategies. New Phytol., 93: 157-191.

Rivkin, R.B., Seliger, H.H., Swift, E. and Biggley, W. (1982). Light shade adaptation by the oceanic dinoflagellates Pyrocistis noctiluca and P. pusiformis. Mar Biol., 68: 181-192.

Stevens, S.E.Jr, Balkill, D.L. and Paoane, D.A.M. (1981). The effects of nitrogen limitation on the ultrastructure of the cyanobacterium Agmenellum quadruplicatum. Arch. Microbiol., 130: 204-212.

Strickland, J.D. and Parsons, T.R. (1968). A practical handbook of seawater analysis. Fish. Res. Board Can. Bull., pp. 167-311.

Sukenik, A., Falkowski, P.G. and Bennett, J. (1987). Potential enhancement of photosynthetic energy conversion in algal mass culture. 1987. Biotech. Bioeng., 30: 970-977.

Talling, J.F. and Driver, D. (1974). General outline of spectrophotometric methods. In: R. A. Vollenweider (ed.), A Manual of Methods for Measuring Primary Production in Aquatic Enviroment. International Programme Handbook No. 12, Blackwell Scientifics Publications, Oxford, pp. 21-26.

Thinh, L-V. (1983). Effect of irradiance on the physiology and ultrastructure of the marine cryptomonad, Cryptomonas strain Lis (Cryptophyceae). Phycologia, 22 (1): 7-11.

Thinh, L-V. (1988). Photoadaptation of photosynthesis in Cryptomonas strain Lis. Photosynthetica, 22 (3): 405-410.

Ukeles, R. and Rose, W.E. (1976). Observations on organic carbon utilization by photosynthetic marine microalgae. Mar. Biol., 37: $11-28$.

Vrede, T. (1998). Elemental composition (C:N:P) and growth rates of bacteria and Rhodomonas grazed by Daphnia. J. Plank. Res., 20: 3 .

Yamanaka, G. and Glazer, A.N. (1980). Dynamic aspects of phycobilisome structure. Phycobilisome turnover during nitrogen starvation in Synechococcus sp. Arch. Microbiol., 124: 39-47.

Zar, J.H. (1984). Biostatistical Analysis, 2nd edition. Prentice-Hall Inc., New Jersey.

Zhukova, N.V. and Aizdaicher, N.A. (1995). Fatty acid composition of 15 species of marine microalgae. Phytochemistry., 39(2): 351356. 